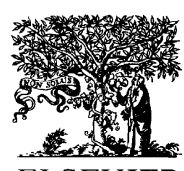

ELSEVIER

Applied Animal Behaviour Science 79 (2002) 133-155

www.elsevier.com/locate/applanim

\title{
Personality traits in the domestic dog (Canis familiaris)
}

\author{
Kenth Svartberg ${ }^{\mathrm{a}, *}$, Björn Forkman ${ }^{\mathrm{b}}$ \\ ${ }^{a}$ Department of Zoology, Stockholm University, S-109 61 Stockholm, Sweden \\ ${ }^{\mathrm{b}}$ Department of Animal Science and Animal Health, The Royal Veterinary and Agricultural University, \\ DK-1870 Frederiksberg, Denmark
}

Accepted 14 June 2002

\begin{abstract}
The domestic dog (Canis familiaris) has been subjected to a huge range of selection pressures during domestication that has resulted in a considerable diversity in morphology and behaviour. This, together with the many uses the dog is put to in our society, makes the dog an interesting model for studies of animal personality. However, only a few attempts have been done to study individual differences in dogs. In this study, behavioural data from 15,329 dogs of 164 different breeds were used to investigate the existence of personality traits in dogs. The data were collected at a personality test that tested the dogs' reactions to strangers, "fleeing" prey-like objects, and several potential fearand aggression-eliciting stimuli. Factor analyses revealed the existence of five narrow traits: "Playfulness", "Curiosity/Fearlessness", "Chase-proneness", "Sociability" and "Aggressiveness". Higher-order factor analyses showed that all factors except "Aggressiveness" were related to each other, creating a broad factor that influences behaviour in a range of situations. Both narrow and broad factors were found in a dataset including data from a large number of breeds, as well as within eight of Fédération Cynologique Internationale's (FCI's) 10 breed groups. This indicates that the personality dimensions found in the study are general for the dog as a species. The finding of a major behavioural dimension in different groups of dog breeds, together with comparable results previously found for wolves (Canis lupus), suggests that the dimension is evolutionarily stable and has survived the varied selection pressures encountered during domestication. The broad factor is comparable to the shyness-boldness axis previously found in both humans and animals, and to human "supertraits" (a combination of Extraversion and Neuroticism). The results of this study can be used to describe and compare individual dogs, as well as breeds. This, in turn, can be used in applications like selection of service dogs and breeding animals, as well as predicting behaviour problems in pet dogs.
\end{abstract}

(C) 2002 Elsevier Science B.V. All rights reserved.

Keywords: Dogs; Personality; Temperament; Individual differences; Shyness-boldness; Aggression

\footnotetext{
* Corresponding author. Tel.: +46-8-16-4054; fax: +46-8-16-7715.

E-mail address: kenth.svartberg@zoologi.su.se (K. Svartberg).
} 


\section{Introduction}

During the last decades there has been an increased interest in the study of behavioural variations between individuals. With this, an earlier view that such differences are merely a bias around a mean has shifted (Slater, 1981), and the findings of individual behavioural differences in animals, consistent over time or across situations, have proven to be useful in the understanding of the evolution of behaviour (e.g. Benus et al., 1991; Wilson et al., 1994) as well as in applied animal behaviour (e.g. Le Scolan et al., 1997; Slabbert and Odendaal, 1999; Grignard et al., 2001).

The results of personality studies in animals have revealed suggestions of human personality traits in different species of animals. The shyness-boldness axis, a fundamental dimension in humans that can be defined as an individual's general tendency to approach novel objects and willingness to take risks (Kagan et al., 1988; Wilson et al., 1994), has been studied and detected in a range of species of different taxa, e.g. octopus (Mather and Andersson, 1993), fish (Wilson et al., 1993), cat (Feaver et al., 1986), and primate (Stevenson-Hinde et al., 1980). For humans, there is today a consensus for the existence of five major human personality dimensions; the "Big Five" (Digman, 1990; Goldberg, 1990; Costa and McCrae, 1992). The Big Five includes the traits Extraversion (associated with sociability and activity), Neuroticism (anxiety and moodiness), Conscientiousness (competence and self-discipline), Agreeableness (trust and compliance), and Openness (fantasy and ideas). There have been attempts to apply this model to nonhuman animals, with some success. Gosling and John (1999) found support for the Big Five in a review including data, mostly from exploratory analyses, from 12 different species. Extraversion, Neuroticism, and Agreeableness were, according to the authors, those factors that showed the strongest cross-species generality. Theory driven research on the personality of animals has mainly focused on Extraversion and Neuroticism. Examples include the work of Broadhurst (1960), Eysenck and Broadhurst (1964) and Garcia-Sevilla (1984), who have used open field test to detect these traits in rodents.

One species that is interesting in the study of animal personality is the domestic dog (Canis familiaris). Dogs are found in great numbers within our own society, yielding good opportunities to make valid behavioural observations. Dogs are held as pets, companion animals, and they are used for different purposes; e.g. as guide dogs, for hunting, herding, and for search for different chemicals like explosives and drugs. This makes knowledge about personality dimensions in dogs important. In addition to this, the dog is an interesting species because of its evolutionary history. In the ancestor of the dog, the wolf (Canis lupus), a major behavioural dimension has been found related to the shyness-boldness axis (Fox, 1972; MacDonald, 1987). During the domestication there have probably been a variety of selective pressures in different places and in different time periods (CluttonBrock, 1999), which have resulted in a variation in morphology, and behaviour as well as in the genome seen in few other species (Coppinger and Schneider, 1995; Clutton-Brock, 1999; Wayne and Ostrender, 1999). If the same personality traits are found both in wolves and dogs of different types and breeds, it is a strong indication of the evolutionary stability of these traits. Despite this, there have been remarkably few attempts to study personality in dogs. In the review by Gosling and John (1999) indications for the traits Extraversion, Neuroticism, Agreeableness and Openness/Conscientiousness were found in 
dogs. However, the studies included in the review assigned subjective interpretations of the behaviour of either individual dogs or in some cases dog breeds (Draper, 1995; Wilsson and Sundgren, 1997; Coren, 1998; Gosling and John, 1998 (in Gosling and John, 1999)). A method that uses fewer initial assumptions is direct observation and strict descriptions of behaviours. Three studies using this methodology on dogs, but with a small number of breeds, are those by Brace (1961) (in Scott and Fuller, 1965) and Goddard and Beilharz (1984, 1985).

The present study is based on behavioural descriptions of 15,329 dogs from 164 breeds collected in a standardised test. The test exposed the dogs to a number of different situations included meetings with strangers, play tests, and several potential fear- and aggression evoking stimuli. We used factor analysis to investigate possible narrow and broad personality traits in dogs.

\section{Methods}

\subsection{Subjects}

The subjects used in this study were in total 15,329 dogs from 164 breeds, including both males and females. The dogs, which were pets living with their owners, were 365 days of age or older when tested. The average test age was 599.6 days (S.D. \pm 323.4 days). For the analyses in this study, the data were separated into two datasets. The first set included data from 25 randomly chosen dogs from all breeds with 25 or more tested dogs (47 breeds: American Staffordshire Terrier, Australian Cattledog, Australian Kelpie, Australian Shepherd, Bearded Collie, Beauceron, Belgian Malinois, Belgian Sheepdog, Belgian Tervuren, Bernese Mountain Dog, Border Collie, Border Terrier, Bouvier des Flandres, Boxer, Briard, Collie (rough), Dalmatian, Danish Fox Terrier, Doberman Pinscher, English Springer Spaniel, Finnish Reindeer Herder, Flat-Coated Retriever, German Shepherd dog, German Shorthaired Pointer, German Spaniel, Giant Schnauzer, Golden Retriever, Greater Swiss Mountain Dog, Hovawart, Iceland Sheepdog, Irish Soft Coated Wheaten Terrier, Irish Terrier, Kerry Blue Terrier, Labrador Retriever, Leonberger, Miniature Schnauzer, Nova Scotia Duck Tolling Retriever, Parson Jack Russell Terrier, Pinscher, Rhodesian Ridgeback, Rottweiler, Russian Black Terrier, Samoyed, Staffordshire Bullterrier, Standard Poodle, Standard Schnauzer, Swedish Vallhund), in total 1175 dogs (611 males, 564 females). By this operation a dataset was constructed that could be assumed to represent dogs in general without the risk of numerously large breeds influencing the results more than smaller breeds. To validate the results from factor analyses on this dataset, and to investigate if the pattern of correlations found was general for different dog types, a second dataset was analysed. This set included data from all dogs, separated into breed groups according to the official breed classification by Fédération Cynologique Internationale (FCI). The FCI classification is based on the breeds' history regarding function and geographic distribution, and separates dog breeds into 10 groups. All 10 breed groups were represented in the sample (Group 1, Sheepdogs and Cattledogs (referred to as "Sheepdogs"): $N=6673$ (34 breeds represented), $51.6 \%$ males; Group 2, Pinschers, Schnauzers, Mastiffs and Swiss mountain and Cattledogs ("Pinschers"): $N=5798$ (29 breeds), $50.3 \%$ 
males; Group 3, Terriers: $N=727$ (21 breeds), 51.4\% males; Group 4, Dachshunds: $N=5$ (1 breed), 80\% males; Group 5, Primitive type dogs and Spitzes ("Primitive dogs"): $N=192$ (22 breeds), 54.7\% males; Group 6, Scent hounds and related breeds ("Scent hounds"): $N=386$ (9 breeds), 50.0\% males; Group 7, Pointing dogs ("Pointers"): $N=92$ (12 breeds), 52.2\%; Group 8, Retrievers, Water dogs and Flushing dogs ("Retrievers"): $N=1298$ (16 breeds), 54.2\% males; Group 9, Companion and Toy dogs ("Companion dogs"): $N=138$ (15 breeds), 54.3\% males; Group 10, Sighthounds (5 breeds): $N=20,80 \%$ males). However, data from Dachshunds and Sighthounds were not used in this study because of the low number of tested dogs. By this separation, analyses within breed groups could be carried out, and the results could be compared with the results from analyses of the first dataset.

\subsection{Testing procedure: general}

The data were collected during a standardised behavioural test ("dog mentality assessment", DMA), which is used by the Swedish Working Dog Association (SWDA; Fält, 1997a). The test was developed mainly as a tool for dog breeding of working dogs. Using the test the behavioural reactions of the parents and, later on, of the progenies can be compared (Fält, 1997b). The test is now used for other breeds than working breeds, and has in many breed clubs in Sweden come to be considered a general behavioural test, which can reveal a dog's reactions to different stimuli.

In the test, the dogs are exposed to several different novel situations and their reactions are described according to a standardised score sheet by official observers, one at every test. During the test the dog is accompanied by a handler, in most cases its owner or another person well known to the dog. A test-leader (TL) is responsible for the practical aspects of the test. All persons conducting the test are trained and certified by SWDA. The training programme for observers is conducted in several steps in which the observer is trained to score dogs' reaction in the test according to pre-set standards. Emphasis is put on an objective and neutral description of the behaviour and the inter-observer reliability is tested several times during the training.

The data were collected during the years of 1997-2001 from 2017 tests at 235 different testing arenas in Sweden. Two hundred and one official observers scored the dogs' reactions. The scores were reported to SWDA, and further to the Swedish Kennel Club.

\subsection{The test}

The test consists of 10 separate subtests, which are carried out outdoors in a specific order. A handler (the owner or another familiar person) accompanies the dog during the whole test. The subtests of the test are Social contact, Play 1, Chase, Passive situation, Distance-play, Sudden appearance, Metallic noise, Ghosts, Play 2, and Gunshot. The setups for the different subtests are built up in advance at different stations along a path in a wooded area. Dog and handler are not allowed to watch when the test situations are arranged. The functionaries are either visually hidden from the dogs' position, or remain passive until it is time to act. The direction of the wind is taken into consideration in order to avoid disturbances from hidden functionaries. 
At the start of the test, observer and functionaries are positioned before the dog and handler are guided to the first station by the TL. In order to standardise the test situation the TL instructs the handler as to what to do and how to act before and during each subtest. As a rule, the handler is asked to be passive and quiet during the subtests. The TL guides handler and dog from station to station from the first subtest and forward. During the test the official observer, who follows the TL from station to station, describes the dog's reaction in the score sheet. The observer or the handler can terminate the test, for example if the dog shows intense and remaining avoidance reactions.

\subsection{Behavioural rating}

The score sheet contains scales for 33 behavioural variables. The aim of the score sheet is to describe the dogs' behaviour as objectively as possible without inferring subjective opinions (like "good behaviour", "too slow", "fearful”, etc.). All 33 variables are scored from 1 to 5 according to intensity of the behavioural reaction, where a low score equals a low intensity in the dogs' behavioural reaction. Each step in the scale, for each variable, is described on the score sheet. In the presentation of the subtests below only descriptions for steps 1 and 5 of each scale are given. During every subtest 1-5 behavioural reactions are recorded. The variables generally correspond to different phases during each subtest.

\subsection{Description of subtests and behavioural variables}

\subsubsection{Social contact}

The dog's reaction to a stranger is tested and described. Handler and dog approaches a passive person, whom the dog has not met earlier (TL). The TL greets the handler and shakes his hand, after which he greets the dog. The TL takes the leash and takes a short walk $(10 \mathrm{~m})$ with the dog, but without the handler. During the walk the TL stops and pets the dog at a distance from the handler, after which he returns to the handler with the dog. Back with the handler the TL makes physical contact with the dog (bends over the dog and touches the sides of the body, the ears and the region of the mouth). The dog's reaction is described by the following behavioural variables.

2.5.1.1. Greeting reaction. Score from "rejection of greeting" (1), to "intense greeting with jumping and whining" (5). Described during the first phase of greeting.

2.5.1.2. Cooperation. Score from "refusal to walk with stranger" (1), to "high willingness to walk with stranger, combined with intense greeting reactions towards stranger" (5). Described during the short walk.

2.5.1.3. Handling. Score from "rejection of physical contact" (1), to "intense social behaviour towards stranger" (5). Described during the phase of physical contact.

\subsubsection{Play 1}

The dog's interest to play with a stranger is tested and described. The stranger (testleader) gives the handler a strong piece of rag. The handler invites the unleashed dog to 
play with the rag by dragging it on the ground in front of the dog. Before the dog grabs the toy, if the dog is willing to do so, the handler throws it to the TL, who is positioned approximately $4 \mathrm{~m}$ away. He throws the toy back to the handler, who throws it back once more. The TL then throws the rag away from the dog (approximately $10 \mathrm{~m}$ ), which is free to run after and catch it. If the dog grabs it the TL tries to call the dog back. When TL has called the dog back and taken the rag, all steps are repeated once. After this, the TL tries to make the dog interested in the rag by dragging it in front of the dog on the ground. If the dog grabs the rag, the TL "fights" back and carries out an easy tug-of-war during a maximum of $30 \mathrm{~s}$. During this tug-of-war the TL alternates between active pulling and passive holding. The dog's reaction is described by the following behavioural variables.

2.5.2.1. Interest in play. Score from "no interest in the tossing of the rag" (1), to "active play and following of the thrown rag" (5). Described during the first phase of throwing between handler and the TL.

2.5.2.2. Grabbing. Score from "no grabbing" (1), to "immediate and intense grabbing" (5). Described when the TL has thrown the rag away from the dog.

2.5.2.3. Tug-of-war. Score from "no biting at all" (1), to "immediate grabbing the rag with twitches and fighting until the TL releases the rag" (5). Described during the tug-ofwar phase.

\subsubsection{Chase}

The dog's reaction to a small and rapidly moving object is tested and described. An approximately $40 \mathrm{~cm}$ long prey-like object (by fur, or similar material) is fixed to a long thin cord (approximately 50-60 m), which is put in a course around 10 small wheels or poles at ground level. The cord around the wheels forms a zigzag pattern with a corridor of approximately $2.5 \mathrm{~m}$ width. A hidden functionary, who can pull the cord quickly by running away, holds the other end of the cord. This set-up makes it possible to make the object "flee" in an irregular pattern away from the dog. Handler and dog approach the start-point, and the leash is taken off. The object is put into movement and the dog is free to run after it. The object stops when it has passed all wheels. This makes it possible for the dog to run after the object and grab it, and even bring it back to the handler together with the fixed cord. If the dog does not approach the object, the handler takes a walk with the dog to the object, though without allowing the dog to grab it. The test is then repeated once. The dog's reaction is described by the following behavioural variables.

2.5.3.1. Following 1. Score from "no attempts to run after the fleeing object" (1), to "immediate reaction when seeing the object and running towards it with high speed" (5) during first repetition. Described when the object "flees".

2.5.3.2. Grabbing 1. Score from "no attempts to grab the object" (1), to "immediate and intense grabbing combined with holding of the object in at least $3 \mathrm{~s}$ " (5) during first repetition. Described when, and if, the dog approaches the object. 
2.5.3.3. Following 2. Score as "Following 1" at the second repetition.

\subsubsection{Grabbing 2. Score as "Grabbing 1" at the second repetition.}

\subsubsection{Passive situation}

The dog's behaviour during a period without any change in the stimulus situation is tested and described. The dog, leashed but with the possibility to move in the full length of the leash (approximately $2 \mathrm{~m}$ ), walks together with the handler into a position approximately $10 \mathrm{~m}$ from the observer. The handler and functionaries remain in passivity during $3 \mathrm{~min}$. The dog's reaction is described by the following behavioural variable.

2.5.4.1. Activity. Score from "non-active" (1) to "active behaviour with switches between different modes of activity" (5). Described during the whole period.

\subsubsection{Distance-play}

In this subtest, the dog's reaction to a play-inviting and oddly behaving unfamiliar person at a distance away from handler is tested and described. A functionary dressed in a cape with hood is hidden at a distance of approximately $40 \mathrm{~m}$ away from the dog. The handler holds the dog with a grip in the leash. In the beginning the functionary claps his hands to catch the dog's attention. Thereafter he starts to move towards the dog and handler in a crouching manner. When the functionary has moved $3 \mathrm{~m}$, he widens the cape and crouches at the same time. The movement towards the dog and the crouching is repeated twice. The functionary now changes appearance. He un-hoods himself and starts to invite the dog to play by tossing a rag up in the air three times. The functionary thereafter runs to a hiding place and takes off the cape, and the dog is released. If, and when, the dog approaches the functionary, he reveals himself and invites the dog to play by dragging the rag on the ground in front of the dog. If the dog engages in play, after $10 \mathrm{~s}$ the functionary lets go of the rag and remains passive during a period of the same length. If the dog has not engaged in play, the functionary keeps the rag in his hand and stands still during $10 \mathrm{~s}$. After the passivity, the functionary once more tries to engage the dog to play by movements and vocal display during $10 \mathrm{~s}$. These last sequences by the functionary-passivity followed by play invitations - are thereafter repeated once. If the dog does not approach the functionary on his own, the handler supports the dog in steps until the dog approaches or until the last step is carried out:

1. Functionary talks to the dog from the hiding place (during $10 \mathrm{~s}$ ).

2. Functionary reveals himself and tries to attract the dog to him by tossing the rag in the air (during $10 \mathrm{~s}$ ).

3. Handler and dog walk together towards the functionary.

If the dog still hesitates to contact the functionary, the handler and dog take a walk together with the functionary. The dog's reaction is described by the following behavioural variables.

2.5.5.1. Interest. Score from "no interest in functionary" (1), to "repeated attempts to run towards the functionary" (5). Described when the dog is still held by the handler. 
2.5.5.2. Aggression. Score from "no signs of aggression or threat display" (1), to "threat display (growling, snarling, raised hackles, raised tail, etc.) directed against the functionary during both phase of threat and invitation" (5). Described when the dog is still held by the handler.

2.5.5.3. Exploration. Score from "no approach attempts towards the functionary, even when he is actively calling the dog" (1), to "immediate approach, even to the passive functionary" (5). Described after the release of the dog.

2.5.5.4. Tug-of-war. Score from "no attempts to play tug-of-war" (1), to "immediate attempts to play with active pulling even when functionary is passive" (5). Described when, and if, the dog is in close proximity to the functionary.

2.5.5.5. Play invitation. Score from "no interest in the functionary" (1), to "urgent play invitations from the dog to the functionary, even when he is passive" (5). Described when, and if, the dog is in close proximity to the functionary.

\subsubsection{Sudden appearance}

The dog's reaction to a suddenly appearing human-like dummy is tested and described. The set-up for this subtest is a boiler suit arranged in such a way that it can be suddenly pulled up in front of the dog. The legs of the dummy are fastened to the ground. The arms of the dummy are attached to ropes that lead up to a wooden batten, horizontally fixed between two trees approximately $2 \mathrm{~m}$ up. The ropes are led through metal loops fastened in the batten, and further away to a functionary who can pull up the dummy. In the starting position the dummy is laid down tight on the ground, and is therefore not visible for the dog. Handler walks the dog in a long loose leash straight towards the place of the dummy. When the dog is $3 \mathrm{~m}$ from the dummy, it is suddenly pulled up. The handler stops at the same time and releases his grip of the leash. The handler remains passive during $15 \mathrm{~s}$, which gives the dog opportunity to freely approach and investigate the dummy. If the dog does not approach the dummy on his own, the handler supports the dog in steps until the dog approaches the dummy or until the last step is carried out:

1. Handler approaches the dummy halfway.

2. Handler approaches the dummy.

3. Handler talks to the dummy and touches it, and calls the dog.

4. Handler returns to the dog, while the dummy is taken down and laid on the ground by the TL. After which the handler together with the dog walk back to the dummy.

The test-leader instructs the handler throughout all these steps (each step is $15 \mathrm{~s}$ ). When the dog has investigated the dummy, or the last step is carried out, the handler takes the dog on a walk close to the dummy. Ten meters beyond the dummy the handler turns back, and once again passes the dummy. This is repeated twice. The dog's reaction is described by the following behavioural variables.

2.5.6.1. Startle reaction. Score from "short hesitation" (1), to "a flight of $>5 \mathrm{~m}$ " (5). Described when the dummy appears. 
2.5.6.2. Aggression. Score from "no signs of aggression, or threat display" (1), to "threat display and attacks against dummy" (5). Described at and after the sudden appearance of the dummy.

2.5.6.3. Exploration. Score from "great need of support (no approach of dummy until handler lowers it and sits close to it), or no approach" (1), to "immediate approach to dummy without need of support" (5). Described after the appearance of the dummy.

2.5.6.4. Remaining avoidance behaviour. Score from "no signs of avoidance behaviour (e.g. no evasive manoeuvre or reduction of speed)" (1), to "significant avoidance behaviour during all passes by the dummy" (5). Described during the repeated walks.

2.5.6.5. Remaining approach behaviour. Score from "no interest in the dummy" (1), to "approaches, together with grabbing and/or playing with the dummy, in at least two passings" (5). Described during the repeated walks.

\subsubsection{Metallic noise}

The dog's reaction to metallic noise is tested and described. A chain with large links is resting on a sheet of corrugated metal (approximately $1.5 \mathrm{~m} \mathrm{long}$ ), which lies horizontally on the ground. A rope is fixed to the chain. A functionary, who is hiding from the dog at a distance, holds the other end of the rope. This arrangement makes it possible to create a metallic noise by pulling the rope. The metal sheet and chain are placed $1.5 \mathrm{~m}$ at the side of a trail, on which the handler and dog walks during the subtest. The rope is pulled when the dog's front passes the metal sheet. When this happens, the handler stops and releases the grip on the leash. The handler remains passive during $15 \mathrm{~s}$, which gives the dog opportunity to freely approach and investigate the source of the noise. If the dog does not approach the source of the noise on his own, the handler supports the dog in steps until the dog approaches it or until the last step is carried out.

1. Handler approaches the sheet of metal halfway.

2. Handler approaches the sheet of metal.

3. Handler touches the sheet of metal without causing any noise, and calls the dog.

The test-leader instructs the handler throughout these steps (each step lasts for $15 \mathrm{~s}$ ). When the dog has investigated the sheet of metal, the handler takes the dog for a walk close to it. Ten meters beyond the sheet the handler turns back, and once again passes it. This is repeated twice. The dog's reaction is described by the following behavioural variables.

2.5.7.1. Startle reaction. Score from "short hesitation" (1), to "a flight of $>5 \mathrm{~m}$ " (5). Described when the chain is pulled over the sheet of corrugated metal.

2.5.7.2. Exploration. Score from "no approach of the sheet of metal, even if handler sits close to it" (1), to "immediate approach without need of support" (5). Described after the noise. 
2.5.7.3. Remaining avoidance behaviour. Score from "no avoidance behaviour (e.g. no evasive manoeuvre or reduction of speed)" (1), to "significant avoidance behaviour during all passes by the source of noise" (5). Described during the repeated walks.

2.5.7.4. Remaining approach behaviour. Score from "no approaches or looks towards the source of noise" (1), to "approaches, together with grabbing and/or playing with the chain, in at least two passings" (5). Described during the repeated walks.

\subsubsection{Ghosts}

The dog's reaction to two slowly approaching persons covered in white sheets ("ghosts") is tested and described. Two functionaries who wear white sheets covering the whole body except for the head are used in this subtest. Over the head the functionaries have white plastic buckets with holes for the eyes. The outlines of the eyeholes, as well as the mouth, are marked in black to make them salient against the white background.

At the beginning of the test the two ghosts hide $20 \mathrm{~m}$ from the dog and handler, who are positioned at the starting point. The distance between the hidden ghosts is $25 \mathrm{~m}$, forming a triangle with ghosts in two corners and dog together with handler in the remaining corner.

During this first phase of the subtest the dog is on leash with opportunity to move in the full length of the leash. Initially, both ghosts move out slowly from the hiding places. After that, one ghost at the time moves towards handler and dog in several short intermittent stages ( $3 \mathrm{~m}$ for each stage). All movements are slow with constant speed. The TL, from a position beyond handler and dog, instructs the functionaries by hand signals through these movements. The ghosts are stopped at a distance of about $4 \mathrm{~m}$ from the dog or, if the dog has positioned himself behind the handler, $4 \mathrm{~m}$ from the handler. The functionaries, after they have come into position in front of the dog, turn around and expose their backs to the dog. After that the handler releases the leash, which enables the dog to investigate one or both ghosts while the handler remains passive. If the dog does not investigate the functionaries on his own, the handler is instructed to move towards the ghosts in steps until the dog attempts to contact them or until the last step is carried out.

1. Handler approaches one of the ghosts halfway (the one the dog seems to be most focused on).

2. Handler approaches the ghost.

3. Handler talks to one of the ghosts, and calls for the dog.

4. Handler helps the ghosts undress.

5. Functionaries (ghosts) attract the dog vocally.

The test-leader instructs the handler to carry out these steps (each step lasts for $15 \mathrm{~s}$ ). After the dog has contacted and greeted one of the ghosts the same undressing-procedure is repeated with the other ghost. The dog's reaction is described by the following behavioural variables.

2.5.8.1. Aggression. Score from "no signs of aggression or threat display" (1), to "threat displays and several attacks against the ghosts" (5). Described while the ghosts approach the dog. 
2.5.8.2. Attention towards ghosts. Score from "occasional glances towards the ghosts" (1), to "constant staring and activity towards ghosts during the whole period of approaching" (5). Described during the period while the ghosts approach the dog.

2.5.8.3. Avoidance behaviour. Score from "constant position ahead or beside handler" (1), to "flight away from the ghosts longer than the length of the leash" (5). Described during the period while the ghosts approach the dog.

2.5.8.4. Exploration. Score from "no approach, at least not before step 4 above" (1), to "immediate approach after the dog is unleashed" (5). Described after the dog is unleashed.

2.5.8.5. Contact with ghosts. Score from "avoidance of the ghosts during the contact phase" (1), to "intense greeting with jumping and whining" (5). Described after the dog is unleashed.

\subsubsection{Play 2}

This subtest is a repetition of "Play 1", with the exception of the final tug-of-war. Description of behaviour is the same as for Interest in play and Grabbing.

\subsubsection{Gunshot}

The dog's reaction to gunshots is tested and described. A functionary with a starter's gun (9 $\mathrm{mm}$ ) hides $20 \mathrm{~m}$ away from the starting point, were the leashed dog and handler are positioned. During the first phase of this subtest the handler tries to play tug-of-war with the dog using a rag. If the dog is not willing to play, the handler is instructed to engage the dog in some other activity (like running together). After $15 \mathrm{~s}$ of activity the first shot is fired. The handler is instructed not to react at the moment of fire and to keep up the activity. This is repeated once, where after the activity is interrupted. During passivity two more gunshots are fired. During the passive phase, the dog has opportunity to freely move in the full length of the leash. If the dog flees longer than the length of the leash the handler releases it. The dog's reaction is described by the following behavioural variable.

2.5.10.1. Avoidance reaction. Score from "none or small reaction in response to the noise with no remaining affect" (1), to "remaining anxiety where the dog interrupts play or activity and show attempts to flee" (5). Described during the whole subtest.

\subsection{Data treatment and statistical analyses}

The patterns of correlation among the behavioural variables were studied using factor analyses. Common factor analyses were used in favour of principal component analyses because the method is better suitable for identifying latent dimensions, especially when there is little knowledge about specific and error variance (Hair et al., 1998). The communalities were estimated by computing the diagonal of the correlation matrix as the multiple $R$-square of the respective variable with all other variables. The criterion of eigenvalue $>1$ was used in each factor analysis. The primary factors were rotated using the Varimax normalised rotation method. In order to investigate whether there was any broader 
construct to which the primary factors related to, a higher-order, or second-order, factor analysis was carried out. When using oblique rotation the primary factors are not constrained to be orthogonal. By this procedure, possible correlations between primary factors can be found and higher-order factors can be revealed. Factor analyses, both primary and second-order, were done with a sample that consisted of data from 1175 dogs ( 25 randomly picked individuals from 47 breeds). The same analyses were also done on the data from all dogs in 8 of the 10 breed groups of the FCI-classification. This was done despite the fact that two of these eight breed groups had lower variable-to-case ratio than 1:5, an often-used lower boundary to create a stable matrix of correlation (Hair et al., 1998). The risk with unstable matrix of correlation taken into consideration, cautious interpretations of the results may however give valuable information of the generalisability of the factors between dog types. The statistical package used was STATISTICA ${ }^{\mathrm{TM}}$.

\section{Results}

The factor analysis based on the data from 25 randomly picked dogs from 47 breeds $(N=1175)$ extracted five primary factors with eigenvalues $>1$ (Table 2). Any loading of 0.40 or above is considered highly significant for this sample size (Hair et al., 1998), and was used as a criterion when considered the relevancy of the variable loading on each factor. Twenty-seven of the 33 behavioural variables fulfilled this criterion for any of the five factors. The first factor had seven high loadings and was the factor that explained the greatest proportion of variance $(11.0 \%)$. Five variables from the two Play subtests loaded on this factor. In addition, two play-variables from the subtest Distance-play had loadings $>0.50$. However, these two variables also loaded high on the fourth factor $(0.47-0.48)$, which suggests that these variables are less representative for this factor. Based on the pattern of loadings, this first factor was labelled "Playfulness". The second factor had both positive and negative high loadings: positive loadings from the three exploration variables in the subtests of Sudden appearance, Metallic noise and Ghosts, negative loadings from Startle reaction and Remaining avoidance behaviour from subtests Sudden appearance and Metallic noise. The second factor was labelled "Curiosity/Fearlessness". The third factor was related to one subtest: Chase. All four variables from this subtest loaded high, which made the label "Chase-proneness" appropriate. The fourth factor was loaded by three variables from the subtest Social contact and the Greeting variable from Ghosts subtest, together with three variables from Distance-play (two of them also loading high on factor "Playfulness"). The factor was labelled "Sociability". The fifth and final factor was loaded by four variables from three subtests: The Aggression variables from subtest Distance-play, Sudden appearance and Ghosts. In addition, the variable Attention from the Ghost subtest had loading $>0.40$. This factor was labelled "Aggressiveness". The loadings of each variable, and the factor labels, are presented in Table 1.

A higher-order (or second-order) factor analysis, which can reveal broader constructs that the primary factors are related to, revealed one secondary factor. Four of the five primary factors-"Playfulness", "Curiosity/Fearlessness", "Chase-proneness", and "Sociability" - had loadings well $>0.40(0.54-0.74)$ on this general factor (Table 2). The loading for the factor "Aggressiveness" was 0.30 , which indicates that this primary 
Table 1

Results from the factor analysis

\begin{tabular}{|c|c|c|c|c|c|c|c|}
\hline \multirow[t]{2}{*}{ Subtest } & \multirow[t]{2}{*}{ Variable } & \multicolumn{5}{|c|}{ Primary factors } & \multirow{2}{*}{$\begin{array}{l}\text { Secondary } \\
\text { factor }\end{array}$} \\
\hline & & Playfulness & Curiosity/Fearlessness & Chase-proneness & Sociability & Aggressiveness & \\
\hline \multirow[t]{3}{*}{ Social contact } & Greetings & 0.06 & 0.06 & 0.07 & 0.59 & 0.11 & 0.38 \\
\hline & Cooperation & 0.11 & 0.02 & 0.04 & 0.59 & 0.05 & 0.36 \\
\hline & Handling & 0.09 & 0.08 & 0.01 & 0.61 & -0.01 & 0.36 \\
\hline \multirow[t]{3}{*}{ Play 1} & Interest in play & 0.70 & 0.04 & 0.16 & 0.18 & 0.16 & 0.55 \\
\hline & Grabbing & 0.72 & 0.02 & 0.12 & 0.06 & 0.11 & 0.47 \\
\hline & Tug-of-war & 0.66 & 0.12 & 0.12 & 0.18 & 0.12 & 0.53 \\
\hline \multirow[t]{4}{*}{ Chase } & Following 1 & 0.09 & 0.11 & 0.71 & 0.10 & 0.07 & 0.39 \\
\hline & Grabbing 1 & 0.15 & 0.14 & 0.72 & 0.06 & 0.06 & 0.41 \\
\hline & Following 2 & 0.16 & 0.10 & 0.72 & 0.11 & -0.01 & 0.43 \\
\hline & Grabbing 2 & 0.23 & 0.12 & 0.70 & 0.07 & 0.04 & 0.44 \\
\hline Passive situation & Activity & 0.09 & -0.03 & 0.04 & 0.04 & 0.10 & 0.09 \\
\hline \multirow[t]{5}{*}{ Distance-play } & Interest & 0.19 & 0.11 & 0.13 & 0.14 & 0.32 & 0.30 \\
\hline & Aggression & -0.02 & -0.08 & -0.09 & -0.13 & 0.46 & -0.03 \\
\hline & Exploration & 0.34 & 0.23 & 0.23 & 0.50 & -0.09 & 0.56 \\
\hline & Tug-of-war & 0.57 & 0.20 & 0.17 & 0.48 & -0.05 & 0.64 \\
\hline & Play invitation & 0.51 & 0.17 & 0.12 & 0.47 & -0.02 & 0.58 \\
\hline \multirow[t]{5}{*}{ Sudden appearance } & Startle reaction & 0.01 & $-\mathbf{0 . 5 3}$ & -0.01 & -0.09 & -0.11 & -0.20 \\
\hline & Aggression & 0.10 & -0.07 & 0.04 & 0.01 & 0.50 & 0.13 \\
\hline & Exploration & 0.09 & 0.63 & 0.05 & 0.11 & -0.10 & 0.31 \\
\hline & Remaining avoidance & -0.08 & -0.62 & 0.02 & -0.06 & 0.02 & -0.26 \\
\hline & Remaining approach & 0.06 & -0.13 & 0.14 & 0.03 & 0.12 & 0.07 \\
\hline \multirow[t]{4}{*}{ Metallic noise } & Startle reaction & -0.04 & -0.56 & -0.06 & -0.02 & -0.03 & -0.24 \\
\hline & Exploration & 0.11 & 0.52 & 0.13 & 0.04 & 0.17 & 0.32 \\
\hline & Remaining avoidance & -0.07 & -0.54 & -0.01 & -0.03 & -0.11 & -0.25 \\
\hline & Remaining approach & 0.06 & -0.19 & 0.06 & 0.08 & 0.05 & 0.05 \\
\hline Ghosts & Aggression & 0.06 & 0.05 & 0.04 & -0.01 & 0.64 & 0.16 \\
\hline
\end{tabular}


Table 1 (Continued)

\begin{tabular}{|c|c|c|c|c|c|c|c|}
\hline \multirow[t]{2}{*}{ Subtest } & \multirow[t]{2}{*}{ Variable } & \multicolumn{5}{|c|}{ Primary factors } & \multirow{2}{*}{$\begin{array}{l}\text { Secondar } \\
\text { factor }\end{array}$} \\
\hline & & Playfulness & Curiosity/Fearlessness & Chase-proneness & Sociability & Aggressiveness & \\
\hline & Attention & 0.01 & 0.05 & 0.04 & 0.12 & 0.50 & 0.20 \\
\hline & Avoidance & -0.03 & -0.27 & 0.03 & -0.19 & 0.14 & -0.16 \\
\hline & Exploration & 0.02 & 0.43 & 0.03 & 0.25 & -0.07 & 0.27 \\
\hline & Greeting & 0.04 & 0.26 & 0.07 & 0.43 & 0.08 & 0.35 \\
\hline \multirow[t]{2}{*}{ Play 2} & Interest in play & 0.78 & 0.10 & 0.16 & 0.04 & 0.13 & 0.53 \\
\hline & Grabbing & 0.78 & 0.09 & 0.16 & -0.01 & 0.11 & 0.51 \\
\hline Gunshot & Avoidance & -0.13 & -0.18 & -0.13 & -0.05 & -0.04 & -0.20 \\
\hline $\begin{array}{l}\text { Proportion of explained } \\
\text { variance }(\%)\end{array}$ & & 11.0 & 7.8 & 7.2 & 6.7 & 4.3 & \\
\hline
\end{tabular}

The result of factor analysis based on a sample including 1175 dogs of 47 breeds reveals five primary factors (with eigenvalue $>1$ ) and one secondary factor. The numbers represent the loading of each variable on the factors. Loadings on the primary factors equal or $>0.40$, which can be considered as relevant in this sample, are in bold. 
Table 2

Results from higher-order factor analyses

\begin{tabular}{|c|c|c|c|c|c|c|}
\hline Sample & Playfulness & $\begin{array}{l}\text { Curiosity/ } \\
\text { Fearlessness }\end{array}$ & $\begin{array}{l}\text { Chase- } \\
\text { proneness }\end{array}$ & Sociability & Aggressiveness & $\begin{array}{l}\text { Playfulness } \\
\text { at distance }\end{array}$ \\
\hline $\begin{array}{l}\text { Dataset } 1 \\
\quad(47 \text { breeds })\end{array}$ & 0.74 & 0.54 & 0.56 & 0.70 & 0.30 & - \\
\hline Sheepdogs & 0.77 & 0.60 & 0.63 & 0.58 & 0.24 & - \\
\hline Pinschers & 0.74 & 0.52 & 0.61 & 0.64 & 0.28 & - \\
\hline Terriers & 0.70 & 0.35 & 0.58 & 0.64 & 0.21 & - \\
\hline Primitive dogs & $\begin{array}{l}0.53 \\
0.51\end{array}$ & $\begin{array}{r}\mathbf{0 . 6 3} \\
-0.16\end{array}$ & $\begin{array}{l}0.17 \\
0.60\end{array}$ & $\begin{array}{l}\mathbf{0 . 6 7} \\
0.15\end{array}$ & $\begin{array}{r}-0.16 \\
\mathbf{0 . 5 1}\end{array}$ & - \\
\hline Scent hounds & 0.71 & 0.31 & 0.61 & 0.71 & 0.14 & - \\
\hline Pointers ${ }^{\mathrm{a}}$ & 0.63 & 0.22 & 0.56 & 0.38 & -0.16 & 0.69 \\
\hline Retrievers $^{\mathrm{b}}$ & 0.63 & 0.55 & 0.50 & - & 0.10 & - \\
\hline Companion dogs & 0.75 & 0.20 & 0.51 & 0.24 & 0.07 & 0.71 \\
\hline
\end{tabular}

The table presents the results from the higher-order factor analysis for the sample including 1175 dogs from 47 breeds, as well as the results from the analyses within each of the eight FCI-breed groups. The numbers represent the loadings of the primary factors on the higher-order factor, i.e. the correlation between primary factors and higher-order factor. Loadings of 0.40 or above are in bold.

a Two secondary factors were extracted in this breed group: one resembling the pattern found in other breed groups (presented here) and one with loadings from mainly two primary factors; "Curiosity/Fearlessness" and a factor specific for this group (loadings from the two variables Remaining approach in addition to Activity).

b "Playfulness" and "Sociability" were in this breed group merged into one factor, here presented as "Playfulness".

factor is less related to the secondary factor. This pattern is supported by the pattern of loadings from the variables on the secondary factor (Table 1). The variables related to "Aggressiveness" have relatively low loadings on the secondary factor $(0.03-0.20)$, compared to the variables representing "Playfulness" (0.47-0.64), "Curiosity/Fearlessness" (0.20-0.32), "Chase-proneness" (0.39-0.41) and "Sociability" (0.35-0.38).

\subsection{Factors within breed groups}

Even though the factor analysis described above is based on data from a large number of breeds there is a possibility that the correlation structure of the variables is different in different dog types due to variation in selection history. To test the generality of the extracted factors factor analyses were, therefore, made within eight breed groups. The result showed a pattern of correlations that generally agreed with the result from the original analysis (Table 3). The factor "Chase-proneness" had the same pattern of relevant loadings within all eight breed groups, as well as in the original analysis. The factor "Curiosity/Fearlessness" was represented in the same way in most of the breed groups as it was in the original analysis. The three variables from subtests Sudden appearance had high loadings in all groups. The same pattern was found for the subtest Metallic noise, with the exception of the variable Remaining avoidance, which had lower loadings in two groups (Pointers and Retrievers). In all breed groups, as well as in the original analysis, the variable exploration from subtest Ghosts loaded $>0.40$, or near, on this factor. In addition, 
Table 3

The results from the factor analyses within eight breed groups (classification according to the FCI)

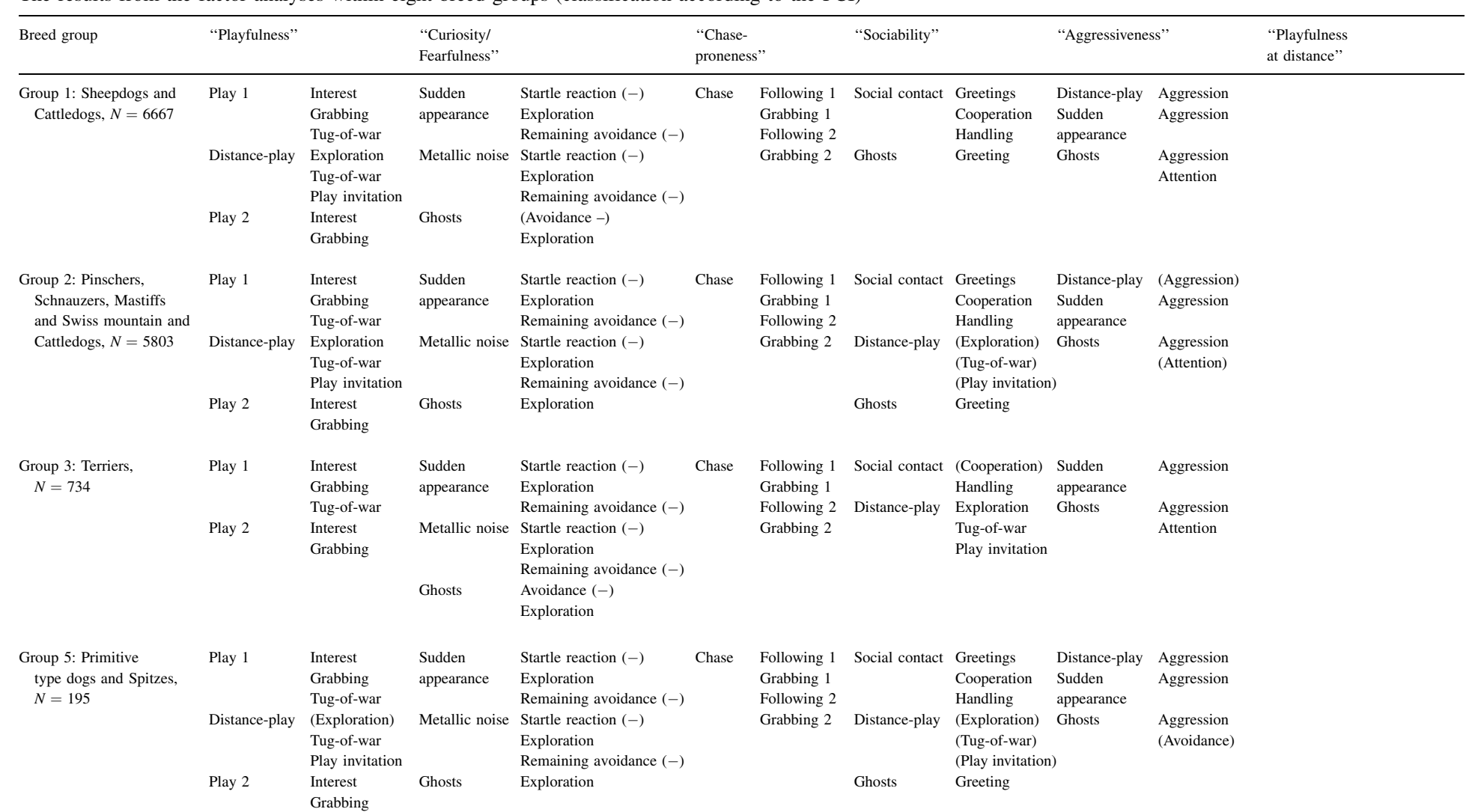




\begin{tabular}{|c|c|c|c|c|c|c|c|c|c|c|c|c|}
\hline \multirow{6}{*}{$\begin{array}{l}\text { Group 6: Scent hounds } \\
\text { and related breeds, } \\
N=383\end{array}$} & Play 1 & $\begin{array}{l}\text { Interest } \\
\text { Grabbing }\end{array}$ & $\begin{array}{l}\text { Sudden } \\
\text { appearance }\end{array}$ & $\begin{array}{l}\text { Startle reaction }(-) \\
\text { Exploration }\end{array}$ & \multirow[t]{6}{*}{ Chase } & $\begin{array}{l}\text { Following } 1 \\
\text { Grabbing } 1\end{array}$ & Social contact & $\begin{array}{l}\text { (Cooperation) } \\
\text { (Handling) }\end{array}$ & Distance-play & $\begin{array}{l}\text { (Interest) } \\
\text { Aggression }\end{array}$ & & \\
\hline & \multirow{5}{*}{ Play 2} & Tug-of-war & & Remaining avoidance $(-)$ & & Following 2 & Distance-play & Exploration & Sudden & Aggression & & \\
\hline & & Interest & Metallic noise & Startle reaction $(-)$ & & Grabbing 2 & & Tug-of-war & appearance & & & \\
\hline & & Grabbing & & Exploration & & & & Play invitation & Ghosts & Aggression & & \\
\hline & & & & Remaining avoidance $(-)$ & & & & & & Attention & & \\
\hline & & & Ghosts & $\begin{array}{l}\text { Exploration } \\
\text { (Greeting) }\end{array}$ & & & & & & & & \\
\hline \multirow[t]{6}{*}{$\begin{array}{l}\text { Group 7: } \text { : }^{\mathrm{a}, \mathrm{b}} \\
\quad \text { Pointers, } N=92\end{array}$} & \multirow[t]{2}{*}{ Play 1} & $\begin{array}{l}\text { Interest } \\
\text { Grabbing }\end{array}$ & $\begin{array}{l}\text { Sudden } \\
\text { appearance }\end{array}$ & $\begin{array}{l}\text { Startle reaction }(-) \\
\text { Exploration }\end{array}$ & \multirow[t]{6}{*}{ Chase } & $\begin{array}{l}\text { Following } 1 \\
\text { Grabbing } 1\end{array}$ & Social contact & $\begin{array}{l}\text { Greetings } \\
\text { Cooperation }\end{array}$ & Distance-play & $\begin{array}{l}\text { Interest } \\
\text { Aggression }\end{array}$ & Distance-play & $\begin{array}{l}\text { Exploration } \\
\text { Tug-of-war }\end{array}$ \\
\hline & & Tug-of-war & & Remaining avoidance $(-)$ & & Following 2 & & Handling & Sudden & Aggression & & Play invitation \\
\hline & \multirow[t]{4}{*}{ Play 2} & Interest & Metallic noise & Startle reaction $(-)$ & & Grabbing 2 & Ghosts & Greeting & appearance & & & \\
\hline & & Grabbing & & Exploration & & & & & Ghosts & Aggression & & \\
\hline & & & Ghosts & Exploration & & & & & & Attention & & \\
\hline & & & & & & & & & & Exploration (-) & & \\
\hline \multirow{11}{*}{$\begin{array}{l}\text { Group } 88^{\mathrm{c}} \text { Retrievers, } \\
\text { Water Dogs and } \\
\text { Flushing dogs, } \\
N=1295\end{array}$} & \multirow[t]{3}{*}{ Social contact } & Greetings & Sudden & Startle reaction $(-)$ & \multirow[t]{11}{*}{ Chase } & Following 1 & & & Distance-play & (Aggression) & & \\
\hline & & Cooperation & appearance & Exploration & & Grabbing 1 & & & Sudden & (Aggression) & & \\
\hline & & Handling & & Remaining avoidance $(-)$ & & Following 2 & & & appearance & & & \\
\hline & Play 1 & Interest & Metallic noise & Startle reaction $(-)$ & & Grabbing 2 & & & Ghosts & Aggression & & \\
\hline & & Grabbing & & Exploration & & & & & & Attention & & \\
\hline & & Tug-of-war & Ghosts & (Avoidance - ) & & & & & & & & \\
\hline & Distance-play & Exploration & & Exploration & & & & & & & & \\
\hline & & Tug-of-war & & & & & & & & & & \\
\hline & & Play invitation & & & & & & & & & & \\
\hline & Play 2 & Interest & & & & & & & & & & \\
\hline & & Grabbing & & & & & & & & & & \\
\hline \multirow{7}{*}{$\begin{array}{l}\text { Group 9: }{ }^{\text {a }} \\
\text { Companions } \\
\text { and Toys, } \\
N=137\end{array}$} & Play 1 & Interest & Sudden & Startle reaction $(-)$ & \multirow[t]{7}{*}{ Chase } & \multirow{7}{*}{$\begin{array}{l}\text { Following } 1 \\
\text { Grabbing } 1 \\
\text { Following } 2 \\
\text { Grabbing } 2\end{array}$} & \multirow[t]{3}{*}{ Social contact } & \multirow{7}{*}{$\begin{array}{l}\text { Greetings } \\
\text { Cooperation } \\
\text { Handling } \\
\text { Greeting }\end{array}$} & \multirow{7}{*}{$\begin{array}{l}\text { Distance-play } \\
\text { Sudden } \\
\text { appearance } \\
\text { Ghosts }\end{array}$} & Aggression & \multirow[t]{7}{*}{ Distance-play } & \multirow{7}{*}{$\begin{array}{l}\text { Exploration } \\
\text { Tug-of-war } \\
\text { Play invitation }\end{array}$} \\
\hline & & Grabbing & appearance & Exploration & & & & & & Aggression & & \\
\hline & & Tug-of-war & & Remaining avoidance $(-)$ & & & & & & & & \\
\hline & Distance-play & Interest & Metallic noise & (Startle reaction -) & & & Ghosts & & & & & \\
\hline & & (Tug-of-war) & & Exploration & & & & & & Aggression & & \\
\hline & & (Play invitation) & & Remaining avoidance $(-)$ & & & & & & Attention & & \\
\hline & Play 2 & Interest & Ghosts & Avoidance $(-)$ & & & & & & & & \\
\hline
\end{tabular}


and different from the original analysis, variable Ghost-Avoidance loaded high, and negatively, in four breed groups, and variable Ghost-Greeting loaded high in one group. A similar slightly heterogeneous pattern was found for the factor Aggressiveness. The Aggression variables from subtests Sudden appearance and Ghosts had high loadings in all groups. The Aggression variable in the subtest Distance-play, as well as the variable Attention from subtest Ghosts were highly or moderately loaded in seven of the eight breed groups. Different from the pattern found in the original analysis, the variable GhostAvoidance loaded on this factor in two groups (Primitive dogs and Pointers), and the variable exploration from the Ghost subtest loaded high and negative in one breed group (Pointers).

In the original analysis, three variables from subtest Distance-play (exploration, tug-ofwar and play invitation) had high loadings on both factor "Playfulness" and "Sociability", which indicates that these variables measure something that is influenced by the dog's degree of playfulness and interest in strangers. These further analyses confirm that the three Distance-play variables represent a tendency in the dogs that is related to both "Playfulness" and "Sociability", but are also slightly separated from these two dimensions. In all breed groups but one the two factors "Playfulness" and "Sociability" are found, whereas the three Distance-play variables are in different breed groups differently related to the two factors. Three patterns were found: (1) the Distance-play variables loads higher on "Playfulness" compared to "Sociability" (Sheepdogs, Pinschers, and Primitive dogs), (2) the Distance-play variables load higher on "Sociability" compared to "Playfulness" (Terriers and Scent hounds), and (3) the Distance-play variables form one specific factora "Playfulness at distance"-factor-besides the factors "Playfulness" and "Sociability" (Pointers and Companion dogs). In breed group Retrievers a more unique pattern was found. The factor "Playfulness" — including the variables from subtest Distance-playand factor "Sociability" were here merged into one major "Sociability-Playfulness"factor. Together with a factor found in Pointers, with high loadings from the variables Remaining interest (Sudden Appearance and Metallic noise) and Activity (Passive situation), this factor is the only one in the analyses within breed groups that has no counterpart in the original analysis.

In summary, even though the pattern of loadings varied slightly between breed groups, the five factors found in the original analysis, together with a possible sixth factor ("Playfulness at a distance from handler"), were found in all FCI-breed groups that were analysed. In order to see if the relationship between those primary factors in the original analysis is general, second-order factor analyses were carried out within each breed group. These second-order factor analyses revealed one secondary factor in six breed groups (Sheepdogs, Pinschers, Terriers, Scent hounds, Retrievers, and Companion dogs) and two secondary factors in two breed groups (Primitive dogs and Pointers). One major factor with loadings similar to the one found in the original analysis was found in most of the breed groups. In Sheepdogs, Pinschers and Retrievers the pattern of highly loaded primary factors was exactly the same (considering that "Playfulness" and "Sociability" were merged into one factor in Retrievers), and close to it in Terriers and Scent hounds. In these groups "Curiosity/Fearlessness" had loadings close to 0.40 on the secondary factor. In one breed group (Primitive dogs) one factor, compared to what was expected from the original analysis, had low loadings ("Chase-proneness"). In the remaining two breed 
groups (Pointers and Companion dogs) two primary factors loaded low or moderately. The loading from each primary factor on the secondary factor/factors is presented in Table 2.

\section{Discussion}

The results from the factor analyses in this study give evidence for personality traits in dogs with cross-situational stability. Five narrow dimensions have been revealed, which have been labelled "Playfulness", "Curiosity/Fearlessness", "Chase-proneness", "Sociability" and "Aggressiveness". In addition, one broad personality dimension, which influences behaviour in a range of test situations, is also revealed. This higher-order personality factor correlates positively to playfulness, interest in chase, exploratory behaviour and sociability towards strangers, and negatively to avoidance behaviour. The broad personality dimension do not relate to aggressive behaviour, which is indicated by low correlations between the "Aggressiveness" factor, as well as the behavioural variables representing "Aggressiveness", and the higher-order factor.

The analyses within breed groups show that the factors are general for dogs, and not due to specific selection pressures in a few dog types. The factors "Curiosity/Fearlessness", "Chase-proneness" and "Aggressiveness" from the original analysis are found in all eight groups with only small, if any, differences in variable loadings. Also "Sociability" and "Playfulness" are found to be general, with the exception of one breed group-Retrievers, Water dogs and Flushing dogs_-where "Playfulness" and "Sociability" are merged into one-dimension. Further, the results suggest that three variables from subtest Distance-play, which measures the dog's tendency to interact and play with an unfamiliar person at a distance from the handler, form a separate factor that represents a dimension related to both playfulness and sociability. The broad dimension is evident in a similar way as in the original analysis in almost all breed groups. "Aggressiveness" is in all breed groups less related to the broad dimension than the other four primary factors. A major part of the few deviations found in variable loadings and factor structure is found in Pointers and Companion dogs. This could be explained by the few number of dogs in these groups, which can lead to unstable matrixes of correlations.

The data, which this study is based on, are collected in a large number of test situations in different arenas and with several official observers scoring the dogs' reactions during the tests. Because of the large number of observers and testing arenas used the data are noisy. However, the functionaries were well trained and the test arenas were as standardised as possible in a test like this. There is no reason to believe that there is any systematic variation that influences the results of the study. The relationships between variables, which create factors, could not be caused by variations between test situations. What could be caused by erroneous variation between tests is a larger variation within the dogs behavioural reactions not caused by different personalities or temperaments. Even if this makes the score for individual dogs less reliable, it should not affect the pattern of correlations between variables in such a large sample. However, the low degree of variation explained by the five primary factors, $37 \%$, could possibly be due to variation in test situations.

The primary factors depend to a great extent on the construction of the test, and how the behavioural responses are described in the specific situations. The factor analysis is 
sensitive to correlating variables, irrespective of whether they come from different subtests or from a single test situation. Therefore, factors with loadings from only one subtest, as "Chase-proneness", can be caused by situation specific parameters, and do not necessarily say anything about the generality of the trait. Because of this, it is necessary to be careful with generalisations. However, in support of the validity of the primary factors is the fact that they all, except "Chase-proneness", are associated with variables from more than one subtest. Factors "Playfulness", "Curiosity/Fearlessness", "and Aggressiveness" seem to be general, based on the spread of loadings from at least three subtests for each factor. If the reactions are consistent from one subtest to another, it is likely that the factor, which the variables correlate to, relates to a stable and general personality trait.

Further support for the primary factors found in this study, is that their counterparts have been found in other species. Dimensions similar to the factor "Sociability" — consistent differences in reactions to strangers and handling-have been reported in several mammals, both in domestic species (e.g. horses: Le Scolan et al., 1997) and in captive nondomestic species (e.g. spotted hyenas: Gosling, 1998). Social playfulness, as in factor "Playfulness", is also something which has been seen as a personality trait, for example in primates (e.g. Hoof, 1973; McGuire et al., 1994). The factor "Curiosity/Fearlessness", analogue to fearfulness, but inverted, seems to be detectable in many species, as a review by Gosling and John (1999) indicates. They found factors related to Neuroticism, with fear and "nerve stability" as core elements, in nine out of 12 reviewed species. A general tendency of fearfulness, which influences approach and avoidance behaviour in a range of situations has also been found earlier in dogs (Goddard and Beilharz, 1984). The factor "Aggressiveness" has counterparts in dimensions found previously in other species (e.g. cats: Feaver et al., 1986; pigs: Forkman et al., 1995; rhesus monkeys: Bolig et al., 1992) as well as in dogs. Royce (1955) investigated data from five breeds by factor analysis. One of the extracted factors was related to aggressive behaviour in different situations. Goddard and Beilharz (1985) also found consistent tendencies of Aggressiveness in dogs. The last factor, "Chase-proneness", is the factor with the least correspondence in other animals. This could be due to the specificity of test situation from which all loading variables come from, a situation that is not included in personality tests in animals in general. Another explanation could be that the type of behavioural reactions the factor corresponds to is species-specific. The running and grabbing of the rag is related to predation, and more specifically the canine way of hunting (Fox, 1969; Coppinger et al., 1987). In the ancestor of the dog, the wolf, there are documented individual differences in killings of living prey (Fox, 1972; MacDonald, 1987). The "Chase-proneness" factor in dogs, which is associated with tendencies to run after and grab an artificial prey, might be analogous to prey killing in wolves.

The higher-order factor, which relates to playfulness, exploration, interest in chase and sociability, indicates that to a great extent it is one single dimension that influences the dogs' behaviour during the whole test. There are previous studies that indicate the existence of a similar major behavioural dimension in dogs. Brace (1961) (in Scott and Fuller, 1965) found one general behavioural dimension related to activity in several test situations and performance in different intelligence and problem-solving tests. This dimension, which was labelled "Activity-success", ranged from "...general good performance and active, confident, behaviour..." to "...timidity, or fear, particularly of 
strange apparatus but also involving some fear of human beings..." (Scott and Fuller, 1965, pp. 374-375). Similarly to the results in the present study, this behavioural dimension was unrelated to aggressive behaviour.

Goddard and Beilharz (1985) reported a similar result when they described the social behaviour of dogs in different situations. Two principal components were extracted from the variables describing the dog's behaviour in the interaction with the test-dogs. The factors were labelled Confidence and Aggression-dominance, respectively. The factor Confidence had high positive loadings for approach, social exploration, high tail position and tail wagging, while biting was negatively correlated to this factor. The other factor was correlated with behaviour related to dominant behaviour: high tail position in combination with lack of tail wagging, and aggressive behaviour as raised hackles and bites. These results can be combined with an earlier study by the same authors (Goddard and Beilharz, 1984), in which the same dog's fearfulness in other situations was investigated. Three fearrelated factors were correlated (inversely) to the factor Confidence, but not to the factor Aggression-dominance, which indicates that dogs that show low confidence when meeting unknown dogs are generally fearful.

The results from previous studies supports the finding in the present study of a broad personality dimension general in different types and breeds of dogs. This indicates that this trait has survived differences in selection pressures during the domestication. Also in the ancestor of the dog, the wolf (Canis lupus), a similar major behavioural dimension has been found. A close relationship between reactivity, exploration and prey-killing ability in 7.5-9 weeks old wolves was reported by Fox (1972). The most fearless pups, in response to different novel stimulus, were also more exploratory, dominant, and showed less hesitation to kill in a prey-situation with live rats, compared to more fearful individuals. Interestingly, the scores collected at young age correlated well with dominance rank at one year of age. Fox's results are, at least in parts, supported by results from another wolf study by MacDonald (1987). The similarity between this behavioural dimension found in wolves and the broad dimension revealed in dogs indicates that the two-dimensions are analogous. This, in turn, suggests that the dimension is evolutionarily stable, and originates from before domestication of the dog took place.

Such broad dimensions have also been detected in other species, and might be analogous to the boldness-shyness continuum. This dimension has been found in humans (Kagan et al., 1988), related to the supertraits Extraversion and Neuroticism (Zuckerman, 1991; Matthews and Deary, 1998), and in a range of other species from different taxa (reviewed in Wilson et al., 1994). The characteristics of the broad dimension found in this study is largely in agreement with the general description of the axis: Shy individuals are generally cautious, timid and evasive in novel situations-both in social and in non-social situations-while bolder individuals are more spontaneous, social, and exploratory.

\section{Conclusion}

Our results give evidence for the existence of a five narrow personality traits in the domestic dog_-"Playfulness", "Curiosity/Fearlessness", "Chase-proneness", "Sociability" and "Aggressiveness" — and a broad personality dimension that relates to all narrow 
traits with the exception of "Aggressiveness". Interestingly, the broad dimension, which is supported by earlier studies in dogs, can be detected in a single test session. The dimension has similarities with major personality traits found in other studies. One of them is the shynessboldness continuum, which could be seen as a combination of the two supertraits Extraversion and Neuroticism. The results of this study can be used for a better description and comparison of individual dogs and breeds. This, in turn, can be useful for selecting individual dogs for specific purposes, e.g. service dogs and suitable breeding dogs. It is also possible that the test result, which gives the dogs score on each of the five factors, can predict behaviour in other situations. This could make the test useful for prediction, and prevention, of different behavioural problems, like aggression towards humans and other dogs.

\section{Acknowledgements}

We thank the Swedish Kennel Club and the Swedish Working Dog Association for the permission to use the data in this study. Thanks also to Per-Erik Sundgren, who placed the software at our disposal that helped us to manage the data in the database. The Swedish Air Force and The Swedish Working Dog Association supported this study financially. Finally, we are grateful to all of you who have contributed in the development of the behavioural test and in the collection of these data, not least all dog owners. You made this study possible.

\section{References}

Benus, R., Bohus, B., Koolhas, J., van Oortmerssen, G., 1991. Heritable variation for aggression as a reflection of individual coping strategies. Experientia 47, 1008-1019.

Bolig, R., Price, C.S., O’Neill, P.L., Suomi, S.J., 1992. Subjective assessment of reactivity level and personality traits of rhesus monkeys. Int. J. Primatol. 13, 287-306.

Brace, C.L., 1961. Physique, physiology, and behavior: an attempt to analyze a part of their roles in the canine biogram. Ph.D. thesis. Harvard University.

Broadhurst, P.L., 1960. Applications of Biometral Genetics to the Inheritance of Behavior. Experiments in Personality. Routledge \& Kegan Paul, London.

Clutton-Brock, J., 1999. A Natural History of Domesticated Mammals. Cambridge University Press, Cambridge.

Coppinger, R., Schneider, R., 1995. Evolution of working dogs. In: Serpell, J. (Ed.), The Domestic Dog: Its Evolution, Behaviour and Interactions with People. Cambridge University Press, Cambridge, pp. 21-47.

Coppinger, R., Glendinning, J., Torop, E., Matthay, C., Sutherland, M., Smith, C., 1987. Degree of behavioral neoteny differentiates canid polymorphs. Ethology 75, 89-108.

Coren, S., 1998. Why We Love the Dogs We Do: How to Find the Dog that Matches Your Personality. Free Press, New York.

Costa, P.T., McCrae, R.R., 1992. Four ways five factors are basic. Personal. Indiv. Differ. 13, 653-665.

Digman, J.M., 1990. Personality structure: emergence of the five-factor model. Annu. Rev. Psychol. 41, 417-440.

Draper, T.W., 1995. Canine analogs of human personality factors. J. Gen. Psychol. 122, 241-252.

Eysenck, H.J., Broadhurst, P.L., 1964. Introduction. Part II. Experiments with animals. In: Eysenck, H.J. (Ed.), Experiments in Motivation. Pergamon Press, Oxford.

Feaver, J., Mendl, M., Bateson, P., 1986. A method for rating the individual distinctiveness of domestic cats. Anim. Behav. 34, 1016-1025.

Forkman, B., Furuhaug, I.L., Jensen, P., 1995. Personality, coping patterns, and aggression in piglets. Appl. Anim. Behav. Sci. 45, 31-42. 
Fox, M.W., 1969. Ontogeny of prey-killing behavior in Canidae. Behaviour 35, 259-272.

Fox, M.W., 1972. Socio-ecological implications of individual differences in wolf litters: a developmental and evolutionary perspective. Behaviour 41, 298-313.

Fält, L., 1997a. Anvisningar Mentalbeskrivning. Svenska Brukshundklubben.

Fält, L., 1997b. Kompendium Mentalitet. Svenska Brukshundklubben.

Garcia-Sevilla, L., 1984. Extraversion and Neuroticism in rats. Personal. Indiv. Differ. 5, 511-532.

Goddard, M.E., Beilharz, R.G., 1984. A factor analysis of fearfulness in potential guide dogs. Appl. Anim. Behav. Sci. 12, 253-265.

Goddard, M.E., Beilharz, R.G., 1985. Individual variation in agonistic behaviour in dogs. Anim. Behav. 33, 1338-1342.

Goldberg, L.R., 1990. An alternative 'Description of personality': the Big Five factor structure. J. Personal. Soc. Psychol. 59, 1216-1229.

Gosling, S.D., 1998. Personality dimensions in spotted hyenas (Crocuta crocuta). J. Compar. Psychol. 112, $107-118$.

Gosling, S.D., John, O.J., 1998. Personality dimensions in dogs, cats, and hyenas. In: Proceedings of the Paper Presentation at the Annual Meeting of the American Psychological Society, Washington, DC.

Gosling, S.D., John, O.J., 1999. Personality dimension in nonhuman animals: a cross-species review. Curr. Direct. Psychol. Sci. 8, 69-75.

Grignard, L., Boivin, X., Boissy, A., Le Neindre, P., 2001. Do beef cattle react consistently to different handling situations? Appl. Anim. Behav. Sci. 71, 263-276.

Hair, J.F., Anderson, R.E., Tatham, R.L., Black, W.C., 1998. Multivariate Data Analysis. Prentice-Hall, Upper Saddle River.

Hoof, J.A.R.A.M., 1973. A structural analysis of the social behaviour of a semi-captive group of chimpanzees. In: von Cranach, M., Vine, I. (Eds.), Social Communication and Movement: Studies of Interaction and Expression in Man and Chimpanzee. Academic Press, London, pp. 75-162.

Kagan, J., Reznick, J., Snidman, N., 1988. Biological bases for childhood shyness. Science 240, 167-171.

Le Scolan, N., Hausberger, M., Wolff, A., 1997. Stability over situations in temperamental traits of horses as revealed by experimental and scoring approaches. Behav. Process. 41, 257-266.

MacDonald, K., 1987. Developmental and stability of personality characteristics in pre-pubertal wolves: implications for pack organization and behavior. In: Frank, H. (Ed.), Man and Wolf: Advances, Issues, and Problems in Captive Wolf Research, Dr. W. Junk Publication, Dordrecht, pp. 293-312.

Mather, J.A., Andersson, R.C., 1993. Personalities of octopuses (Octopus rubescens). J. Compar. Psychol. 107, 336-340.

Matthews, G., Deary, I.J., 1998. Personality Traits. Cambridge University Press, Cambridge.

McGuire, M.T., Raleigh, M.J., Pollack, D.B., 1994. Personality features in vervet monkeys: the effect of sex age, social status, and group composition. Am. J. Primatol. 33, 1-13.

Royce, J.R., 1955. A factorial study of emotionality in the dog. Psychol. Monogr. 69, 1-27.

Scott, J.P., Fuller, J.L., 1965. Genetics and the Social Behavior of the Dog. The University of Chicago Press, Chicago.

Slabbert, J.M., Odendaal, J.S.J., 1999. Early prediction of adult police dog efficiency—a longitudinal study. Appl. Anim. Behav. Sci. 64, 269-288.

Slater, P.J.B., 1981. Individual Differences in Animal Behaviour. Perspectives in Ethology. Plenum Press, New York.

Stevenson-Hinde, J., Stillwell-Barnes, R., Zunz, M., 1980. Subjective assessment of rhesus monkeys over four successive years. Primates 21, 66-82.

Wayne, R.K., Ostrender, E.A., 1999. Origin, genetic diversity, and the genome structure of the domestic dog. Bio. Essays 21, 247-257.

Wilson, D.S., Coleman, K., Clark, A.B., Biederman, L., 1993. Shy-bold continuum in pumpkinseed sunfish (Lepomis gibbosus): an ecological study of a psychological trait. J. Compar. Psychol. 107, 250-260.

Wilson, D., Clark, A., Coleman, K., Dearstyne, T., 1994. Shyness and boldness in humans and other animals. Trends Ecol. Evol. 9, 442-446.

Wilsson, E., Sundgren, P.-E., 1997. The use of behaviour test for the selection of dogs for service and breeding. Part I. Method of testing and evaluating test results in the adult dog, demands on different kinds of service dogs, sex and breed differences, sex and breed differences. Appl. Anim. Behav. Sci. 53, 279-295.

Zuckerman, M., 1991. Psychobiology of Personality. Cambridge University Press, Cambridge. 